\title{
Hybrid Natural Disaster mapping and Mitigation Plans
}

\author{
C.Amuthadevi ${ }^{1[0000-0003-1066-5893]}$,Gayathri MonicaSubarnan*2 [0000-0002-5886-1554] \\ D.S.Vijayan 3[0000-0003-0128-5397] \\ ${ }^{1}$ Department of CSE, SRMIST KTR campus, Tamil Nadu, India. \\ ${ }^{2}$ Department of Electrical and Electronics Engineering,SRMIST, Ramapuram Campus, \\ Tamil Nadu, India \\ ${ }^{3}$ Department of Civil Engineering, AarupadaiVeedu Institute of Technology, VMRF, Tamil \\ Nadu, India. \\ 11camuthadevi@gmail.com, 2monigaya5281@gmail.com, ${ }^{3}$ vijayan@avit.ac.in \\ *Corresponding Author: Gayathri Monica Subarnan
}

\begin{abstract}
Many of the natural disasters are threatens the human lives and also assets of the people. Hazard mapping is one way to connect the particular location into kind of hazardous based on the history of the events in the specific geographic zone. The weather changes may trigger into many natural disasters. In this chapter, Multi-hazard is focused. All kinds of natural disasters happened in particular zone like floods, earthquakes, tsunami and landslides for the past years are used for prediction. It will be useful to save many lives and reduce the damages.

This chapter attentions on

$\checkmark$ Hazard category and Cruelty

$\checkmark$ Hazard-mapping

$\checkmark$ Detection of Risk and mapping

$\checkmark$ Awareness Engendering

$\checkmark$ Reserve plan

$\checkmark$ Approaches and plan for evacuation

The hybrid approaches are used by using history of information, prediction strategy by automated learning strategy and real time data collection from satellite images and sensors. Different mitigation plans will be analysed and summarize the useful solutions in the plan.
\end{abstract}

Keywords: Hazard Mapping, Prediction, Mitigation, Evacuation Plan, Natural Hazards

\section{Introduction}

Sufferers by natural hazards and calamities carriage momentous threats to the publics. It becomes a main alarm that with the global warming, and also weather structure drive more inconsistent and the occurrence and cruelty of calamitous proceedings may rise in future. Recently, this alarm has established gradually, added care and it was recommended that natural hazards have converted further expensive in admiration of victims triggered over in past 2 eras [1]. Earthquakes, hot cyclones, landslides, 
floods and forest-fires are most of the causes and create highest loss event and source substantial harm to the community.

Using the occurrence and cruelty of natural threats growing universally, community and natural researchers are revolving the consideration in resiliency, a multi-faceted idea that description differs dependent in the investigator(s) and this kind of study directed [2,3]. Investigate that classifies the weakness within societies and efforts to measure flexibility is ahead momentum.

\subsection{Hazard Category and Cruelty}

Natural Hazards are happening because of sudden or slow on-set of events happening. These categories are listed in the Table 1.

Table 1: Hazard categories

\begin{tabular}{|c|l|l|}
\hline S.No & Hazard Category & \multicolumn{1}{c|}{ Hazard events } \\
\hline 1. & Geography & $\begin{array}{l}\text { earthquakes, landslides, tsunamis and volcanic activi- } \\
\text { ty }\end{array}$ \\
\hline 2. & Hydrology & floods \\
\hline 3. & Climatic & risky temperatures, drought and wildfires \\
\hline 4. & Meteorology & cyclones and hurricanes/wave surges \\
\hline 5. & biology & disease waves and fly/animal outbreaks \\
\hline
\end{tabular}

Human-made disaster comprises ecological deprivation, contamination and accidents. Technical or man-made hazards (multifaceted disasters/struggles, scarcity, expatriate populations, industrial coincidences and transportation accidents). Cruelty of hazards makes the disaster survivors suffers from stress disorder to severe complications such as comorbid stages and need medical treatments [4].

\subsection{Multi-hazards}

When more than single danger in a specified location and the relations among these counting their concurrent or cumulative incidence and the possible connections. A Multi-Hazard Early Warning System (MHEWS) is ableto discourse numerous dangers and/or influences of comparable or dissimilar kind in conditions where dangerous proceedings might happen, concurrently, flowing or cumulatively with time, and captivating into interpretation the possible consistent effects. As most disaster-prone areas in the ecosphere, recurrent natural hazards (range from tsunamis to floods to volcanic eruptions) loom livings of most of the people about the Pacific 
Border and outcome in disastrous obliteration and damage. The fatalities and influences that describe disasters has abundant to do by experience and susceptibility of people and locations as they prepare with the harshness of the danger event.

Although natural dangers/threats will not be eradicated, through distribution of best preparation, information, and investigation, people and government can better know the dangers and diminish the danger to people life. Over the historical period, the Multi-Hazards Hub held by Tohoku University in Sendai, Japan operated to nature of the communal abilities for cutting-edge investigate on the common danger of natural hazards fronting the zone.

\section{$2 \quad$ Related Works}

The initial collection of hazard maps in Indian subcontinent for retort spectrum amplitudes in designated natural aeras with the PSHA method was organized by the training prepared in National Disaster Mitigation Agency (NDMA) [5]. Hazard mapping is used to map the particular zone or location into one of the categories of Hazards. Preparation of hazard maps will be helpful to save many peoples by execution proper plans and strategies. Some zones may fit into multi-hazard mapping parameters.

\subsection{Hazard Mapping}

Iran has zones which have multi hazard prone. Based on the subcategory like floods combined with landslide may affect $70 \%$ of zones [6]. Totally 11 parameters relate to territory and land-usage had been nominated in training of landslide and flood vulnerability mappings. Probabilistic Seismic Hazard Analysis (PSHA) was prepared and the association between the hazards were identified. The founded outcomes by representations had confirmed with ROC (Rate of Change) curves. The resultant AUCs (Area Under Curve) of the proof showed precisions of $84 \%$ \& $80 \%$ for floods and landslides, correspondingly, and $87 \%$ and $82.6 \%$ for flood and landslides founded on the exercise data, correspondingly. Then all hazard maps were collectively generating a multi-hazard likelihood plot of the Lorestan Province and map helps as an appreciated means for land use preparation, supportable substructure change in Lorestan Province.

Heat pressure and forestry fires are repeatedly measured and extremely connected threats, as dangerous temperatures are crucial roles in all occurrences. This cohesion can affect in what way public shield and local respondents position resources on the ground and can prime to an under assessment of possible effects, as individuals can be fewer resilient after uncovered to multi-hazards. In Europe (June 2017) heat and fire affected many lives and the combined event along with the affect- 
ed zones were mapped by Multi-Hazard Early Warning System [7] and can be used for evidence-based detection system.

Heavy water falls causes flash floods and facing this is a very big challenge in all the countries [8]. Rising facts of flash-flood information confirms that the morpho-metric parameters of the catchment regulator and its hydrological retort. From this, the Geomorphological Unit Hydrograph (GUH) was one of the furthermost prevalent approaches for guessing hydrological procedures, if data are insufficient. The technique is grounded on the measurable association among catchment geomorphology (for example, catchment zone and silhouette, geography, and torrent concentration) and hydrological developments.

Earthquake-activating landslides might source fatal actions and grave financial losses [9]. In the earthquake susceptible zone, vulnerability drawing of earthquake- activating landslides was actual significant to safe preparation, disaster supervision, and hazard extenuation. Various representations were useful for landslide vulnerability mapping. For example, heuristic functions, probabilistic methods, and soft-computing approaches, like Artificial Neural Networks (ANN) and Support Vector Machines (SVM).From multiple methods, the conditional probabilistic models were widely practiced. [10].

Mining-induced quakes and seismic earthquakes remain mostly erratic and have a contrary influence in the resident populations and constructions. For this motive, specialist care of this singularity is a difficult task. The claim of interferometric SAR in the assessment of ground drive was carried acceptable outcomes in the previous 20 years largely in the districts wherever no additional dimensions were showed throughout ground subsiding [11].

In the universal gauge, sandy coasts are (because of climate change) progressively unprotected for hazards by coastal floods and corrosion. Predictable variations in temperature may influence the sea level rise, amplified wildness in centre of latitudes, also variations in sea-wave settings by complex waves and tempest flows. Survey says that 24 percentage in ecosphere's sandy coasts take an erosion amount of greater than $0.5 \mathrm{~m} /$ year then around $16 \%$ greater than $1 \mathrm{~m} /$ year. Nearly, $27 \%$ in sandy-coasts remain experiencing deposit and around 18\% take a lump amount completed $1 \mathrm{~m} /$ year. France has $23 \%$ of sandy-coasts remain accreting in that, $40 \%$ are steady and $37 \%$ are corroding. In sandy-coast of Vendee [12], the vulnerability is evaluated by long term and short-term. The danger is evaluated i) using long-term through measurement of past development of seashore among the years 1950 and 2016 ii) through short term through measurement the sudden evacuations owing to dangerous events. 


\subsection{Detection of Risk and mapping}

Acknowledgement of the necessity to tie seeming gap among the research and executive have been recognized, both in the framework of disaster danger and additional normally crossways knowledge to act schemes. Non-Government Organizations show a critical part in dropping risks where clear stages of deficiency and disparity prime to developed susceptibility and disaster influences.

climatical variations style the city zones added and more unprotected to landslide, waterway floods, coastal attrition and marine blizzard proceedings that develop disastrous if deserted by the social order. Susceptibility lessening alone showed to be not sufficient to lessen the penalties of natural events. Resilience is the capability in scheme, civic or civilization bare to hazards to battle, engage, billet, familiarize to, alter and improve after the hazard in a appropriate and effectual way, with by means of the conservation and repair of its vital elementary constructions and purposes over risk management [13].

Hazards can be categorized based on the affected area range from local to global, based on the time period mapping from long term to short term forecasting. Catastrophe modelling permits insurers and reinsurers, economic organizations, companies, and communal works to assess and be able to natural disaster risk from dangers extending from quakes and hurricanes, floods and wildfire. Hazard should be fitted into loss models and shown in the Figure 1.

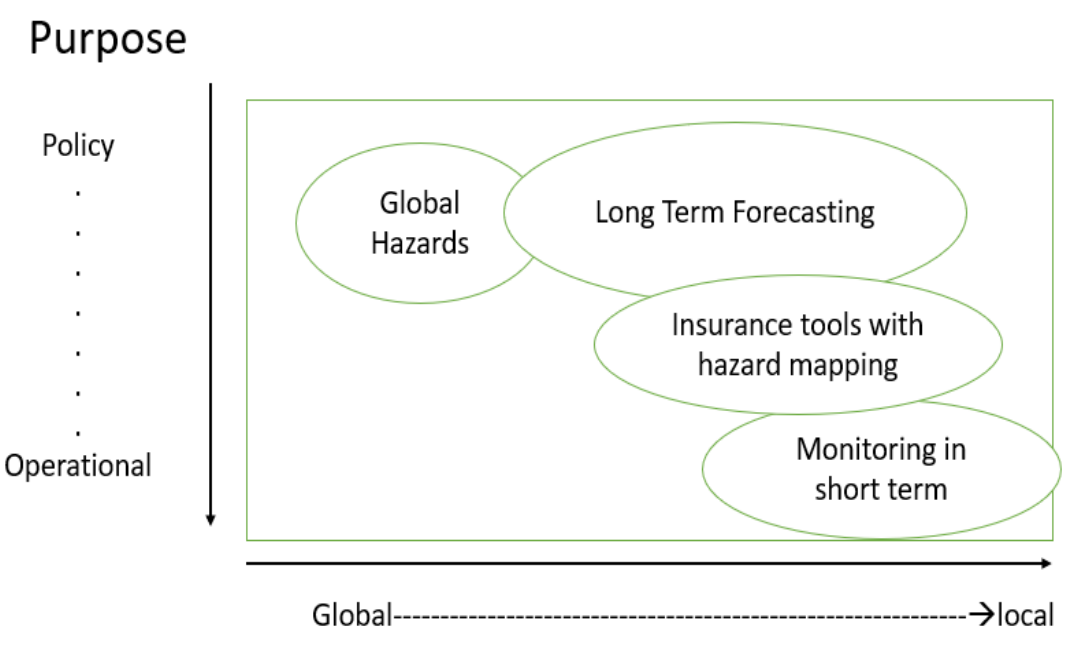

Figure 1: Hazard and Risk Mapping 
Risk mapping includes both risk management and disaster management [14]. The disaster risks supervision reflects all actions that permit the urban to handle through hazardous measures and guarantee the lowermost cost for civilization. The disaster management understands the activities essential to re-establish regularity afterwards the incidence of risky events. Risk managing founds a relationship among its stages (mitigation, preparedness, response, recovery) and flexibility goal line (make for, handle with, retort to, and improve from) to recognize the flexibility status in city system on both longer time (response and recovery) and shorter time (mitigation and readiness phases) durations.

\subsubsection{Mitigation:}

This phase attentions for actions needed to style the public added strong earlier the incidence of dangerous proceedings. For Example, mitigation trials were the variations in resident structure codes, land use administration, retrofitting of buildings to survive usual hazards, defence erections.

\subsubsection{Preparedness:}

This phase intentions are to progress the cognizance of public and their skills to respond compared to hostile events, both in before and after-event, over instructive plans. Evacuation arrangement, the meeting of commercial communal and other actions like supplying necessary food and water which can be passed out throughout this stage. The two stages are connected to make goal line of flexibility what suggests that individuals and organizations were talented to quickly discover the various behaviours to see their requirements throughout the incidence of disastrous proceedings. The attainment of goal might deliver funds to predict the conceivable upcoming situations, establish priorities, and retort. For example, through activating and coordinative broader human, economic and physical capitals.

\subsubsection{Response:}

This phase discourses the activities occupied directly subsequently the incidence of the hazardous events to decrease the damage of survives and properties, bound the significance on structure, environment and to meet the basic requirements (food, water, housing, dress). The renovation of efficacies and belongings as well as the steadying of community facilities are also actions comprehended during emergency time. Response scheduling goals in speedy assessment of the possessions of hazardous events. This is connected with retort and endure goals of flexibility and hinge on the strength, idleness and elasticity of a system. 


\subsubsection{Recovery:}

This phase includes both short-term and long-term activities in reconstruction and renaissance of affected societies, directing in to a grade of physical, ecological, financial and communal constancy. The short-term stage includes transporting instant facilities, counting the renovation of episodic usefulness facilities, the reinstatement of carriage ways and the delivery of food and shelter into expatriate persons, although the long-term stage necessitates planned actions to discourse the impressions of a tragedy. Recovery can be connected to the acclimate resilience goal and absorbed by notionwhere system has methods to endlessly progress and the solutions are founded on the position must be avoided.

Natural hazard danger modelling includes combination of danger influence situations through acquaintance data and susceptibility purposes. The outcome is an estimation of damage, portrayed in numerous conducts counting financial cost; humanoid fatalities; construction of harm states; social disturbance; and other types of significance specified the harshness of the danger.

\section{PREDICTION BY AUTOMATED LEARNING STRATEGY}

Prediction is not a simple method. It differs from zones, time and related to other hazards. Some of the Machine learning approaches with past history of data and evacuation methods executed may be helpful for mapping, and assessment of risks. In the country Indonesia at zone Palu, the intensity of earthquake was analyzed using the clustering method [15]. The following work was done:

i) conducted the cluster investigation to classify the earthquake-expected regions,

ii) established a CNN prototypical for likelihood approximation, and

iii) assessed and comparation of risk by means of 2 calculation equations (Risk 1 and 2).

Due to the greater forecast capability, the CNN prototypical measured the likelihood although Silhouette clustering (SC), Pure Locational Clustering (PLC) were applied to recognize the longitudinal clustering, Euclidean distance between clusters, spatial association and cross-correlation between the projected Mw, PGA and strength counting actions complexity. At last, AHP was applied to evaluate the vulnerability. Earthquake's probability assessment (EPA), susceptibility to seismic amplification (SSA) and earthquake vulnerability assessment (EVA) were used to produce risk 1, although earthquake danger assessment (EHA), SSA and EVA were utilized to make risk B. After that the risk maps were associated and the changes in outcomes were found. This training attained $89.47 \%$ accurateness for EPA although for EVA a constancy 
proportion of 0.07 . All of consequences take significant inferences for forthcoming risk valuation, land use development and threat mitigation.
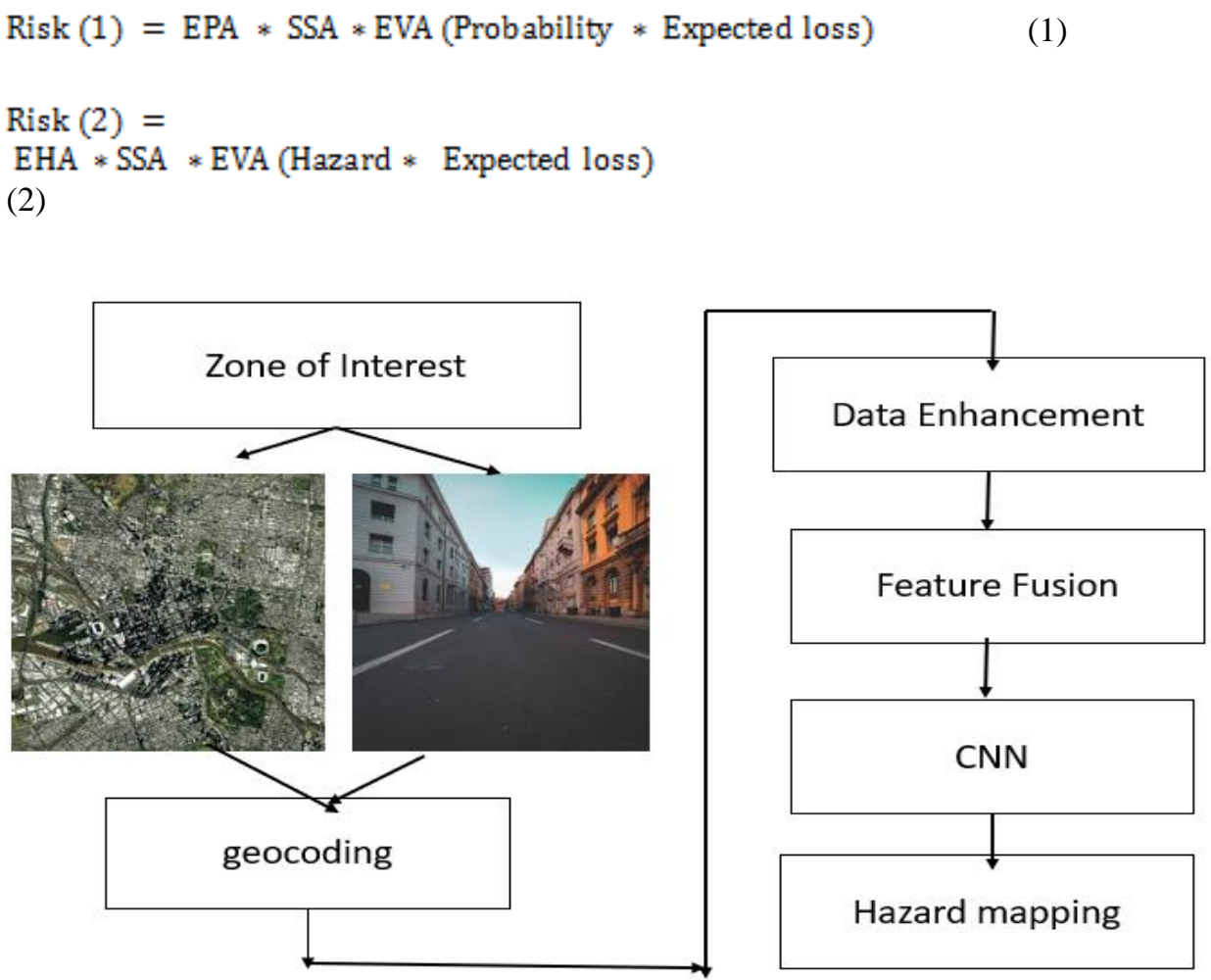

Figure 2: Automatic Prediction Strategy

Collecting the information manually from the affected regions and building a model is a most time consuming and laborious task. To make as fast, the modern technologies such as collection of data from satellite with time and location range can be utilized. Geocoding is the procedure to transform the details about a location like couple of coordinates, or the area name into a position on the ground's surface. User can geocode through giving one place description as input or many places at once as a table. Then, subsequent positions are output with geographic features containing attributes, which will be utilized for plotting or spatial study.

The features collected from the geocoded data; the features of images can be fused to get more information. Then applying convolution Neural Networks (CNN) give output that will be useful information for building the inventory. If noise exists because of uncertain information, pre-processing will be applied for better enhancement [16]. 
After that, Inventory information is mapped to hazard maps which will be useful for prediction and risk management.

\section{PLANS AND APPROACHES FOR EVACUATION}

Sensitivity and risk are the most critical criteria in humanitarian emergency logistics, where most models reduce response times, evacuation time and distance, transport rates, the number of open installations, installation costs or operating expenses, discovered requests, exposed demands and risks, as well as optimising the demand points. Responding to a problem, the problem can be implemented in many ways for various issues, such as verdict theory, queue theory and fuzzy approaches, the problem position problem and other technologies. The main focus of humanitarian emergency supply research was on earthquakes, hurricanes, floods and epidemics across the globe.

The first response to alerts is in most cases successful evacuation. It is so necessary to establish escape routes and refuges. Where assessors target details, the matter is minimized. Evaluating state of crisis and responding behavior, for example, appears to be easier. Application of exercises and incidents will assess alert and evacuation procedures. It is reasonably easy to isolate each variable jointly for review within the preparedness answer system. Early alerts responses are studied on a variety of occasions and thus the efficacy of alert systems is negligible for group attitudes. Such information has helped to assess the situation of early warning systems in refined ways.

The activities of a disaster will be split into 2 phases, one before or proactive, the other after a disaster and the other post-reactive. Humanitarian supply for three phases of Disaster Management (DM) activities is one of the operations concerned: planning, response and recovery.

Humanitarian (HL) is the strategy of evacuating the people from disasterstricken zones to safe places and of preparing for the efficient flow and storing of goods and materials, introducing and dominating them, while aggregating knowledge for the reason of origin to the detriment of the needs of the defenseless people [17], [18].

Expansion and retrofitting of public infrastructure and buildings to satisfy the additional difficult necessities created by international climate change. All new buildings should abide by building standards.

- Improvement of the physical living conditions in depressed rural and concrete areas by increasing the social safety web and rising housing project standards

- Integration of DRM into poorness reduction methods and productive sector programme planning.

- This may increase the resilience of lower financial gain teams whose livelihoods are typically coupled to agriculture, fishing, and different primary activities. 
- Distinctive risk regions around the island and establishing dedicated funds for risk management.

-Adopting bio-engineering solutions in elevated hazard areas, for example shrubs on slopes, in role of onerous engineering.

- Property management of natural resource by using firmer planning controls.

- Enactment of correct management and conservation methods with relevance biodiversity, watersheds, and forestry; and therefore, the implementation of a comprehensive Coastal Zone Management Efforts have recently been focused on strengthening the look of urban avoidance systems and infrastructure to safeguard against flooding [19].

This has enclosed institutional and restrictive risk reduction measures with the technical help of the World Bank. One major goal of this set up is that the improvement of the standard of project management, that is predicted to be increased through relevant trainings, courses, networks and technical guidance.

The subsequent strategic outcomes are anticipated as:

- The introduction of enormous legislation is subject to due regard for adapted laws and rules and a long strategy that reduces the impact of rising water levels, dangerous acts of humans and river meandering

- Right irrigation and violation of areas of growth and production, residential and various special areas of management by appropriate facilities, physical facilities and utilities, modified legislation and economic administrative control and funding.

- In compliance with sectoral and regional development programmes, the structure and physical infrastructure of the transport sector was extended and strengthened and complies with international safety and environmental requirements.

Existing emergency caring logistics' improvement mock-ups consume few limits in large-scale data, this will be complicated to compute and finding the optimal can yield an extreme quantity of period and computation power. So, the event of innovative algorithms that may be useful in emergency caring supplying is important to feature to this stable of genetic algorithms, locate-allocate heuristics. In some situations, 2 disasters might occur, similar to an earthquake followed by a tsunami. Therefore, a lot of analysis is required that considers multi-disaster situations. Combined disaster point managing is additionally necessary within the decision-taking method in emergency caring logistics' facility setting problems. Normally, investigators have continuously targeted on every stage and a couple of studies have targeting combination disaster stage management. Consequently, integrated disaster stage management is recognized as a serious gap that ought to be thought of successful onward [20]. 


\subsection{Essential awareness Disaster categories:}

\subsubsection{Vulnerability valuation:}

Start line for coming up with preparation, coupled to longer-term extenuation and expansion interventions additionally as disaster state.

\subsubsection{Forecasting:}

Coming up with Disaster preparation strategies united in place, that are attainable and that commitment and resources are comparatively assured.

\subsubsection{Organized outline:}

Well-co-ordinated catastrophe preparedness and response scheme in the least grade levels, with promise in applicable stakeholders. Roles and tasks evidently defined.

\subsubsection{Info systems:}

Economical and reliable systems for gathering and sharing information like forecasts and warnings, information on relevant capacities, role allocation and resources between stakeholders.

\subsubsection{Reserve base:}

Product like stocks in food, alternative shelter and alternative resources, facilities like search and rescue, medicinal, engineering, nourishment experts and tragedy liberation money like and also things not just stored or not expected obtainable and available.

\subsubsection{Alert structures:}

Strong communications schemes like skills, substructure, capable of transmission cautions efficiently to public during risk.

\subsubsection{Response devices:}

Recognized and acquainted to disaster response activities and tragedy sufferers may include: evacuation actions and accommodations, exploration and saving squads, wants assessment squads, initiation of also emergency support amenities, response centres and accommodations for evacuated.

\subsubsection{Instruction and coaching:}

Coaching courses, workshops and allowance programmes to at-risk teams and tragedy responders. information of risk and applicable response communal by public information and teaching systems. 


\subsection{Risk reduction after disaster}

Post-disaster assessments, such as Disaster Assessment and Needs Analyses, will allow authorities to evaluate the damage incurred, identify at risk populations, and determine the priorities and resources required for the resumption of normal operations. As part of the rehabilitation phase of the recovery process outlined, the Government will invite international and regional organizations, to compile detailed assessments of the social and economic impact and sectoral damage caused by the disaster. The Plan recognizes that training and capacity building programmes are fundamental elements of professional development for members of the Disaster Assessment and Needs Analysis Disaster Committee and thus form part of the National Emergency Management Organization's annual agenda. The recommendations garnered from Disaster Assessment and Needs Analyses form the basis of post-disaster development plans for resilient reconstruction, and are expected to place on the path to sustainable development.

Post-disaster recovery, a chance for property expansion Underdevelopment and unsuccessful or unsuitable progress programmes rise susceptibility to hazards, and therefore cause a lot of disasters. In turn, emergencies build succeeding development harder for disaster exaggerated societies which had lost the support properties, thus in establishments that are attempting to assist these. The need to incorporate relief, recovery and growth more closely is generally appropriate. This indicates a long-term possibility of post-disaster measures [21]. Different approaches are available specific to disaster[22,23]. In essence, it means that relief and recovery should lead to long-term growth and vulnerability reduction, wherever possible - they should not simply rebuild the current risk. The hope of a "normal" development that will restart shortly after the crisis phase is obviously unreal. Help services and growth programmes must be compelled to adhere. While efforts to protect livelihoods and reduce the risks of food and cash for work will aid, success will rely on smart management.

\subsection{Limitations in success:}

Maximum of arrangements aims to offer financial gain and community amenities, however in practice these 2 aims will be tough to settle. Release and post-relief initiatives tend to work on totally different scales, with mass coverage being a lot of simply attained in relief processes. Preservation of supports is vitally necessary to poor and vulnerable people, and vulnerability is closely connected to living safety. once a tragedy, receiving a legal document shortly be an importance for the sufferers.

Recovery framework incorporates many actions that it hopes will accomplish the following:

- Promoting a come to accessibility of services and also the availability of products which support traditional life. 
- Promoting courses of action which is able to contribute to a discount within the vulnerability of the while this receipts a protracted time to line up a lot of substantial, advanced initiatives attributable to the extent of technical, social control and different inputs required.

- Deprived directing flops to care persons maximum in want or makes divisions among groups through choosing few people and not others. there's still some dialogue regarding the most effective ways of choosing beneficiaries.

- Inadequate designing and consultation, resulting in effort being wasted on mitigation structures that aren't a priority for the community, or won't work.

- Deficiency of assurance by recipients, sometimes since they're not members within the scheme, however are treated simply as employees. this may lead to poor quality of construction. It conjointly makes it less probably that the community will still maintain the newly-built facilities once the food or money payments come back to an end. population to a variety of hazards.

- Stimulating native initiatives to retort to the results and impacts of a disaster.

- Developing plans and techniques to boost the method of long-run rehabilitation.

Chances of success at community level could also be improved by:

- Acting quickly before the worry or enthusiasm for amendment created by the disaster have lessened;

- Basing interventions on acquainted technologies and native resources as way as possible; concentrating on a tiny low range of necessary actions, not introducing a full portfolio of changes that dissipate efforts;

- Specializing in what's possible - communities already hit by a disaster have several pressing issues to attend to, and that they won't respond if they believe the planned mitigation measures are on the far side their reach; and

- Cheering and involving societies as members in change.

This needs earlier involvement, a lot of stress in reconstruction livings and inspiring positive socio-economic alteration.

\section{CONCLUSION AND FUTURE WORK}

Existing emergency caring logistics' improvement mock-ups consume few limits in large-scale data, this will be complicated to compute and finding the optimal can yield an extreme quantity of period and computation power. So, the event of innovative algorithms that may be useful in emergency caring supplying is important to feature to this stable of genetic algorithms, locate-allocate heuristics. In some situations, 2 disasters might occur, similar to an earthquake followed by a tsunami. 


\section{References}

1. David Pitt, Stefan Trück, Rob van den Honert, Wan Wah Wong : Modeling risks from natural hazards with generalized additive models for location, scale and shape, Journal of Environmental Management 275,111075 (2020).

2. S.L. Cutter, L. Barnes, M. Berry, C. Burton, E. Evans, E. Tate, J. Webb: A place-based model for understanding community resilience to natural disasters, Global Environ. Change 18 (4) 598-606, (2008)

3. S. Henly-Shepard, C. Anderson, K. Burnett, L.J. Cox, J.N. Kittinger, M. A. Ka'aumoana : Quantifying household social resilience: a place-based approach in a rapidly transforming community, Nat. Hazards 75 (1) 343-363, (2015)

4. Isa M. Gargano, Robyn R. Gershon, AminotuOgunyemi, Danica Dorlette, Lysa J. Petrsoric, James E. Cone,Comorbid posttraumatic stress disorder and lower respiratory symptoms in disaster survivors: Qualitative results of a 17-year follow-up of World Trade Center disaster survivors, Progress in Disaster Science, Volume 4, 100050, https://doi.org/10.1016/j.pdisas.2019.100050. (2019).

5. Alan Scaria, Ishwer D. Gupta, Vinay K. Gupta: An improved probabilistic seismic hazard mapping of peninsular shield region of India, Soil Dynamics and Earthquake Engineering, 106417, 2020 https://doi.org/10.1016/j.soildyn.2020.106417.

6. Hamid Reza Pourghasemi, Amiya Gayen, Mahdi Panahi, FatemehRezaie, Thomas Blaschke : Multi-hazard probability assessment and mapping in Iran, Science of The Total Environment, Volume 692, Pages 556-571,(2019) https://doi.org/10.1016/j.scitotenv.2019.07.203.

7. Claudia Vitolo, Claudia Di Napoli, Francesca Di Giuseppe, Hannah L. Cloke, Florian Pappenberger, Mapping combined wildfire and heat stress hazards to improve evidence-based decision making, Environment International, Volume 127, Pages 21-34, (2019), https://doi.org/10.1016/j.envint.2019.03.008.

8. Da-wei Zhang, JinQuan, Hong-bin Zhang, Fan Wang, Hong Wang, Xiao-yan He : Flash flood hazard mapping: A pilot case study in Xiapu River Basin, China, Water Science and Engineering, Volume 8, Issue 3, Pages 195-204,( 2015), https://doi.org/10.1016/j.wse.2015.05.002.

9. Keira O Kane : Mapping boundary interactions across earthquake science and humanitarian-development communities for disaster risk reduction, International Journal of Disaster Risk Reduction 49 ,101729,( (2020), https://doi.org/10.1016/j.ijdrr.2020.101729.

10. Chong Xu, Xiwei Xu, Fuchu Dai, Arun K. Saraf : Comparison of different models for susceptibility mapping of earthquake triggered landslides related with the 2008 Wenchuan earthquake in China, Computers \& Geosciences, Volume 46,Pages 317-329,(2012), https://doi.org/10.1016/j.cageo.2012.01.002.

11. Agnieszka A. Malinowska, Wojciech T. Witkowski, ArturGuzy, RyszardHejmanowski:Mapping ground movements caused by mining-induced earthquakes applying satellite radar interferometry, Engineering Geology, Volume 246, Pages 402-411, (2018)https://doi.org/10.1016/j.enggeo.2018.10.013.

12. MorganeAudère, Marc Robin:Assessment of the vulnerability of sandy coasts to erosion (short and medium term) for coastal risk mapping (Vendée, W France), Ocean \& Coastal Management, Volume 201,105452, https://doi.org/10.1016/j.ocecoaman.2020.105452.

13. Ines Alberico , Roberta Iavarone, Paola Petrosino: A procedure for the resilience mapping in urban systems exposed to natural hazard: The Ischia Island (southern Italy) test ar- 
ea, International Journal of Disaster Risk Reduction, 50, 101893, (2020), https://doi.org/10.1016/j.ijdrr.2020.101893

14. Rockefeller Foundation - ARUP City Resilience Framework, 2015. New York, https://www.rockefellerfoundation.org/report/city-resilience-framework/. (Accessed 1 May 2019).

15. Ratiranjan Jena, Biswajeet Pradhan, GhassanBeydoun, Abdullah M. Alamri, Ardiansyah, Nizamuddin, HizirSofyan, Earthquake hazard and risk assessment using machine learning approaches at Palu, Indonesia, Science of The Total Environment, Volume 749, 141582, (2020), https://doi.org/10.1016/j.scitotenv.2020.141582.

16. Chaofeng Wang a, Qian Yu, Kincho H. Law, Frank McKenna, Stella X. Yu, ErtugrulTaciroglu, Adam Zsarn'oczay, WaelElhaddad, BarbarosCetiner : Machine learningbased regional scale intelligent modeling of building information for natural hazard risk management, Automation in Construction, 122, 103474, (2021).

17. M.S. Habib, Y.H. Lee, M.S. Memon Mathematical models in humanitarian supply chain management: a systematic literature reviewMath. Prob. Eng. (2016)

18. A. SauerHumanitarian Supply Chain Performance Management: Development and Evaluation of a Comprehensive Performance Measurement Framework Based on the Balanced Scorecard (Doctoral dissertation) Munich Business School, German (2016)

19. Ding C, Song Y, Knaap G, Huang Y. 2005. Urban planning and spatial structure: urban sustainable development strategy (In Chinese). Beijing: China Architecture \& Building Press.

20. Deb K, Karthik S. 2007. Dynamic multi-objective optimization and decision-making using modified NSGA-II: a case study on hydro-thermal power scheduling. Paper presented at the International conference on evolutionary multi-criterion optimization, Berlin, Heidelberg.

21. John Twigg, 2004 "Disaster risk reduction Mitigation and preparedness in development and emergency programming HPN Humanitarian Practice Network".

22. DS Vijayan, A Leema Rose, S Arvindan, J Revathy, C Amuthadevi, 2020 "Automation systems in smart buildings"Journal of Ambient Intelligence and Humanized Computing.https://doi.org/10.1007/s12652-020-02666-9

23. C Amuthadevi, DS Vijayan, Varatharajan Ramachandran,2021" Development of air quality monitoring(AQM) models using different machine learning approaches "Journal of Ambient Intelligence and Humanized Computing. https://doi.org/10.1007/s12652-02002724-2 